\title{
Can 4\% Articaine Buccal Infiltration Replace Inferior Alveolar Nerve Block (IANB) with 2\% Xylocaine for Pulp Therapy in Primary Mandibular Molars? A Systematic Review
}

\author{
Sunny P Tirupathi ${ }^{1}$, Srinitya Rajasekhar ${ }^{2}$, Mayuri Ganesh ${ }^{3}$, Abhishek Vamshi $^{4}$, David Tyro ${ }^{5}$
}

\begin{abstract}
Aim and objective: This systematic review aims to compare the efficacy of $4 \%$ articaine buccal supraperiosteal/infiltration to that of inferior alveolar nerve block (IANB) with $2 \%$ xylocaine in providing pulpal anesthesia for carrying out pulp therapy of deciduous mandibular molars in children. Materials and methods: PubMed, Cochrane Registry, and Ovid SP were searched in the timeframe between years 1991 and 2020 with appropriate MeSH terms. Full texts were selected only after a preliminary screening of relevant titles and abstracts.

Results: Five studies were involved for the final qualitative analysis. The parameter sought for was "Pain during pulp therapy after injection with buccal supraperiosteal/infiltration ( $4 \%$ articaine) or IANB (2\% lignocaine) in primary mandibular molars. Three studies evaluated objective pain (operator reported) during pulp therapy, reported significantly lower pain scores with articaine buccal infiltration (BI). Among the two studies that evaluated subjective pain, one study reported a significantly lower pain score with the articaine BI group. The other study reported no difference statistically between both groups.

Conclusion: Under the bounds of this systematic review, BI with $4 \%$ articaine might be equivalent to IANB with $2 \%$ lignocaine for providing pulpal anesthesia required for pulp therapy procedures in primary mandibular molars; however, the quality of evidence is low, more number of well-controlled studies with adequate sized sample should be conducted out to verify the same.

Keywords: Articaine, Buccal, Children, Inferior alveolar nerve block, Infiltration, Lignocaine, Pulp therapy.

International Journal of Clinical Pediatric Dentistry (2021): 10.5005/jp-journals-10005-1974
\end{abstract}

\section{INTRODUCTION}

Pain control is the foremost aspect of pediatric dentistry. Inferior alveolar nerve block (IANB) is irrefutably one among the most painful, ${ }^{1}$ and the most important injections for performing invasive procedures like pulp therapies, primary tooth extractions in the mandibular arch in children. Owing to anatomical variations of mandibular foramen which is placed more antero-inferiorly, discomfort can be much more in children during IANB. ${ }^{2}$ Failure rates of IANB are also fairly high which will require additional supplemental anesthesia which is more traumatic to the child. ${ }^{3}$ Articaine is an ester group local anesthetic with a thiopentone ring, which has greater lipid solubility that is claimed to have higher diffusion properties than lignocaine.

Many studies reported that buccal infiltration (BI) alone with articaine can allow its diffusion into palatal tissues and provide sufficient anesthesia for carrying out invasive procedures on maxillary teeth without the need for adjective palatal anesthesia. ${ }^{4-11}$ Similarly, many studies in the adult population have mentioned that buccal supraperiosteal (infiltration) injection alone with articaine is equipotent to IANB with lignocaine. ${ }^{12-17}$

Within the limits of our understanding, no systematic review so far has compared the efficacy of buccal supraperiosteal injection with articaine and IANB with lignocaine in children for the specific outcome of pain related to pulp therapy. The current systematic review aims to compare and evaluate the efficacy of $\mathrm{BI}$ with articaine and IANB with lignocaine in providing pulpal anesthesia for carrying out pulp therapy in primary mandibular molars in children.
1Department of Pedodontics and Preventive Dentistry, Dr DY Patil
Vidyapeeth, Pimpri, Pune, Maharashtra, India
2,3Department of Pedodontics, Malla Reddy Institute of Dental
Sciences, Hyderabad, Telangana, India
4,5Department of Oral Surgery, Malla Reddy Institute of Dental
Sciences, Hyderabad, Telangana, India
Corresponding Author: Sunny PTirupathi, Department of Pedodontics
and Preventive Dentistry, Dr DY Patil Vidyapeeth, Pimpri, Pune,
Maharashtra, India, Phone: +91 9490549454, e-mail: dr.priyatham@
gmail.com
How to cite this article: Tirupathi SP, Rajasekhar S, Ganesh M, et al.
Can 4\% Articaine Buccal Infiltration Replace Inferior Alveolar Nerve
Block (IANB) with 2\% Xylocaine for Pulp Therapy in Primary Mandibular
Molars? A Systematic Review. Int J Clin Pediatr Dent 2021;14(3):420-425.
Source of support: Nil
Conflict of interest: None

\section{Materials and Methods}

\section{Protocol}

This systematic review is compiled according to the PRISMA guidelines. Eligibility criteria: Relevant mesh terms basing on PICO were used to evaluate and search the question "Can buccal infiltration of articaine induce adequate pulpal anesthesia for carrying out pulp therapy in primary mandibular molars".

PubMed, Ovid SP, and Cochrane were searched between the years January 1, 1990, and December 1, 2020. The last search was performed on December 1, 2020. The search was based on the 
pre-set question using appropriate MeSH terms ((articaine) AND (buccal)) AND (dental).

\section{Eligibility Criteria}

Randomized controlled trials (RCTs) which juxtaposed $4 \%$ articaine $\mathrm{BI}$ to IANB with $2 \%$ xylocaine for inducing pulpal anesthesia for pulp therapy in primary mandibular molars were evaluated. Nonrandomized trials, observational studies, narrative and systematic reviews, were excluded. Double articles were removed. Suitable articles were then included for a full-text evaluation (Flowchart 1).

Data analysis was performed by three reviewers. The outcome sought for was "pain during pulp therapy after injection with buccal infiltration or IANB in primary mandibular molars". Only Qualitative analysis of data was carried out, data pooling was not done as there are very few studies are available.

\section{Results}

In the selected databases 550 titles were retrieved, out of them, 6 replicas were removed and 544 titles and abstracts were screened. Full text of the 15 articles was appraised, ${ }^{12-26}$ among them 10 articles were excluded $^{12-17,21,24-26}$ (reasons are presented in Table 1). Five studies sustained the search criteria and were incorporated for the final data fabrication. ${ }^{18-20,22,23}$

\section{Attributes of Included Studies}

The features of the five included studies are represented in Table 2. Among them, two were published in the year 2016 and three were published in 2018.

\section{RoB}

The risk of bias (RoB) was evaluated on seven-point criteria by Cochrane collaboration.

The RoB (Fig. 1) was evaluated according to Cochrane guidelines. Randomization was mentioned in four studies. ${ }^{19,20,22,23}$ Allocation concealment was carried out in two studies, ${ }^{19,23}$ unclear in two studies, ${ }^{20,22}$ and not carried out in one study. ${ }^{18}$ Only two

\begin{tabular}{cll}
\multicolumn{3}{l}{ Table 1: Excluded studies with reasons } \\
\hline S. no. & Excluded articles & Reasons for exclusion \\
\hline 1 & Corbett 2008 & Study was carried out on adults \\
2 & Jung 2008 & Study was carried out on adults \\
3 & Poorni 2011 & Study was carried out on adults \\
4 & Arrow 2012 & $\begin{array}{l}\text { Study was done in children but } \\
\text { evaluated pain during restorative }\end{array}$ \\
& & reasons, not for pulp therapy \\
5 & Monterio 2015 & Study was carried out on adults \\
6 & Bartlett 2016 & Study was carried out on adults \\
7 & Zain 2016 & Study was carried out on adults \\
8 & Venkat Narayan 2017 & Study was carried out on adults \\
9 & Yilimaz 2018 & Study was carried out on adults \\
10 & Jorgenson 2020 & Study was carried out on perma- \\
& & nent first molar in children \\
\hline
\end{tabular}

studies performed blinding of both participants and personnel. ${ }^{20,23}$ Blinding of outcome assessment was done only in three studies. ${ }^{20,22,23}$ Attrition bias is reported in one study. ${ }^{19}$ Selective reporting bias is not present in any of the studies evaluated.

\section{Discussion}

Among the five studies evaluated, three followed the split-mouth design, and two studies followed a parallel arm trial. Children's age in the included articles was between 4 years and 10 years.

In the present systematic review, studies comparing $\mathrm{BI}$ with articaine directly to IANB with lignocaine for the outcome procedural pain related to pulp therapy (access opening, pulp extirpation) are evaluated.

\section{Buccal Infiltration}

Four percent of articaine was used in all the studies. The volume of articaine deposited as $\mathrm{BI}$ ranged between 0.8 and $1.8 \mathrm{~mL}$ across

Flowchart 1: Flowchart

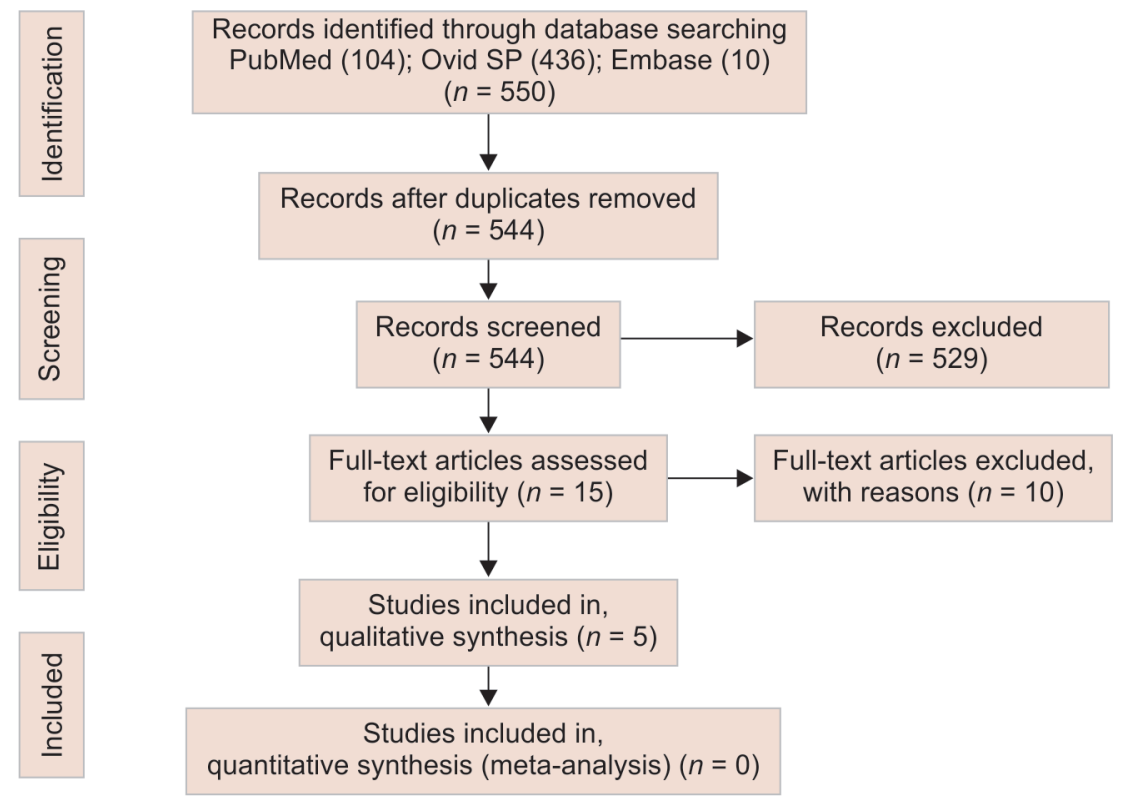




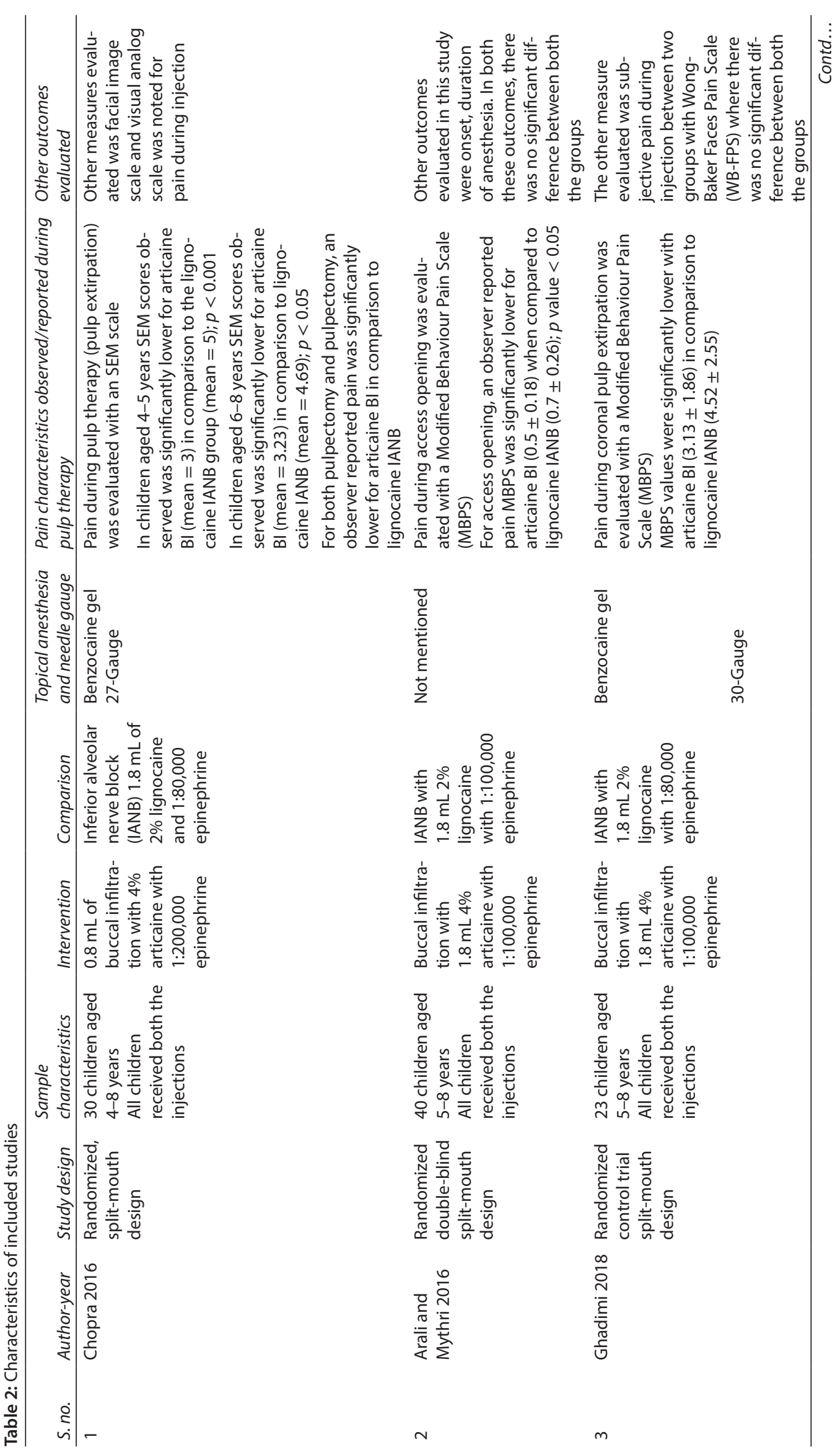



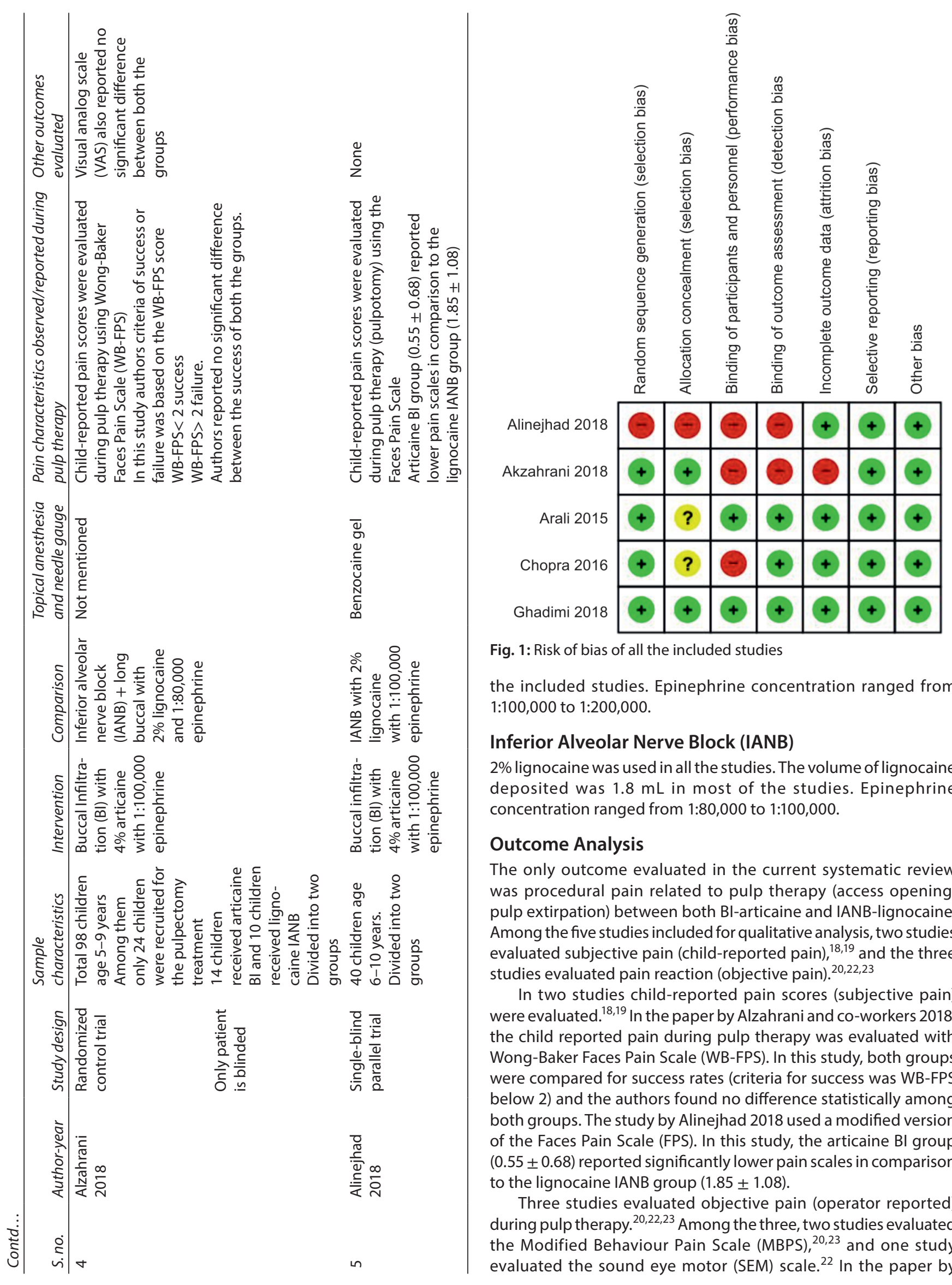

Fig. 1: Risk of bias of all the included studies

the included studies. Epinephrine concentration ranged from $1: 100,000$ to $1: 200,000$.

\section{Inferior Alveolar Nerve Block (IANB)}

$2 \%$ lignocaine was used in all the studies. The volume of lignocaine deposited was $1.8 \mathrm{~mL}$ in most of the studies. Epinephrine concentration ranged from 1:80,000 to 1:100,000.

\section{Outcome Analysis}

The only outcome evaluated in the current systematic review was procedural pain related to pulp therapy (access opening, pulp extirpation) between both BI-articaine and IANB-lignocaine. Among the five studies included for qualitative analysis, two studies evaluated subjective pain (child-reported pain), ${ }^{18,19}$ and the three studies evaluated pain reaction (objective pain). ${ }^{20,22,23}$

In two studies child-reported pain scores (subjective pain) were evaluated..$^{18,19}$ In the paper by Alzahrani and co-workers 2018, the child reported pain during pulp therapy was evaluated with Wong-Baker Faces Pain Scale (WB-FPS). In this study, both groups were compared for success rates (criteria for success was WB-FPS below 2) and the authors found no difference statistically among both groups. The study by Alinejhad 2018 used a modified version of the Faces Pain Scale (FPS). In this study, the articaine BI group $(0.55 \pm 0.68)$ reported significantly lower pain scales in comparison to the lignocaine IANB group $(1.85 \pm 1.08)$.

Three studies evaluated objective pain (operator reported) during pulp therapy. ${ }^{20,22,23}$ Among the three, two studies evaluated the Modified Behaviour Pain Scale (MBPS), ${ }^{20,23}$ and one study evaluated the sound eye motor (SEM) scale. $^{22}$ In the paper by 
Chopra et al. 2016, pain during pulp therapy (pulp extirpation) was evaluated with the SEM scale. In children aged 4-5 years, SEM scores observed were significantly lower for articaine $\mathrm{BI}($ mean $=3)$ in comparison to the lignocaine IANB group (mean $=5)(p<0.001)$. In children aged 6-8 years, SEM scores observed were significantly lower for articaine $\mathrm{BI}($ mean $=3.23)$ in comparison to lignocaine IANB (mean $=4.69)(p<0.05)$. For both pulpotomy and pulpectomy, the observer reported pain was significantly lower for articaine $\mathrm{BI}$ in comparison to lignocaine IANB. ${ }^{22}$ The study by Arali and Mytri 2016 , pain during access opening was evaluated with MBPS, for access opening which was significantly lower for articaine $\mathrm{BI}(0.5 \pm 0.18)$ when compared to lignocaine IANB $(0.7 \pm 0.26)$; $p$ value $<0.05 .{ }^{20}$ The paper by Ghadimi and coworkers 2018, pain due to coronal pulp extirpation was evaluated with MBPS which was significantly lower with articaine $\mathrm{BI}(3.13 \pm 1.86)$ in comparison to lignocaine IANB $(4.52 \pm 2.55)$ group. ${ }^{23}$ All the three studies reported significantly lower observer reported pain scores for articaine $\mathrm{Bl}$ in comparison to lignocaine IANB. ${ }^{20,22,23}$

The other measures evaluated which were not included in the present systematic review were pain during injection, ${ }^{22,23}$ onset, duration of anesthesia, ${ }^{20}$ which revealed no significant difference in both the groups.

\section{Conclusion}

Buccal infiltration with $4 \%$ articaine might be equivalent to IANB with $2 \%$ lignocaine for providing pulpal anesthesia required for pulp therapy procedures in primary mandibular molars however, the quality of evidence is low, more number trials with adequate sample size should be conducted to verify the same.

\section{References}

1. Kaufman E, Epstein JB, Naveh E, et al. A survey of pain, pressure, and discomfort induced by commonly used oral local anesthesia injections. Anesth Prog 2005;52(4):122-127. DOI: 10.2344/0003-3006(2005)52[122:ASP]2.0.CO;2.

2. Hwang TJ, Hsu SC, Huang QF, et al. Age changes in location of mandibular foramen. Zhonghua Ya Yi Xue Hui Za Zhi 1990;9(3): 98-103.

3. Pourkazemi M, Erfanparast L, Sheykhgermchi S, et al. Is inferior alveolar nerve block sufficient for routine dental treatment in 4- to 6-year-old children? Int J Clin Pediatr Dent 2017;10(4):369-372. DOI: 10.5005/jp-journals-10005-1467.

4. Abu Sharkh M, Khalil A, Ong-Ly C, et al. Buccal injection of articaine to anesthetize the palatal mucosa. Gen Dent 2009;67(3):26-30.

5. Al-Mahalawy $\mathrm{H}$, Abuohashish $\mathrm{H}$, Chathoth $\mathrm{S}$, et al. Articaine versus lidocaine concentration in the palatal tissues after supraperiosteal buccal infiltration anesthesia. J Oral Maxillofac Surg 2018;76(2):315. e1-315.e7. DOI: 10.1016/j.joms.2017.10.001.

6. Bataineh AB, Nusair YM, Al-Rahahleh RQ. Comparative study of articaine and lidocaine without palatal injection for maxillary teeth extraction. Clin Oral Investig 2019;23(8):3239-3248. DOI: 10.1007/ s00784-018-2738-x.

7. Hosseini HR, Parirokh M, Nakhaee N, et al. Efficacy of articaine and lidocaine for buccal infiltration of first maxillary molars with symptomatic irreversible pulpitis: a randomized doubleblinded clinical trial. Iran Endod J 2016;11(2):79-84. DOI: 10.7508/ iej.2016.02.001.

8. Kolli NK, Nirmala SV, Nuvvula S. The effectiveness of articaine and lidocaine single buccal infiltration versus conventional buccal and palatal injection using lidocaine during primary maxillary molar extraction: a randomized control trial. Anesth Essays Res 2017;11(1):160-164. DOI: 10.4103/0259-1162.186589.

9. Kumar DP, Sharma M, Patil V, et al. Anesthetic efficacy of single buccal infiltration of $4 \%$ articaine and $2 \%$ lignocaine in extraction of maxillary 1(st) molar. Ann Maxillofac Surg 2019;9(2):239-246. DOI: 10.4103/ams.ams_201_18.

10. Majid OW, Ahmed AM. The anesthetic efficacy of articaine and lidocaine in equivalent doses as buccal and non-palatal infiltration for maxillary molar extraction: a randomized, double-blinded, placebocontrolled clinical trial. J Oral Maxillofac Surg 2018;76(4):737-743. DOI: 10.1016/j.joms.2017.11.028.

11. Sandilya V, Andrade NN, Mathai PC, et al. A randomized control trial comparing buccal infiltration of $4 \%$ articaine with buccal and palatal infiltration of $2 \%$ lignocaine for the extraction of maxillary premolar teeth. Contemp Clin Dent 2019;10(2):284-288. DOI: 10.4103/ccd. ccd_529_18.

12. Bartlett $G$, Mansoor J. Articaine buccal infiltration vs lidocaine inferior dental block - a review of the literature. Br Dent J 2016;220(3):117-120. DOI: 10.1038/sj.bdj.2016.93.

13. Corbett IP, Kanaa MD, Whitworth JM, et al. Articaine infiltration for anesthesia of mandibular first molars. J Endod 2008;34(5):514-518. DOI: 10.1016/j.joen.2008.02.042.

14. Jung IY, Kim JH, Kim ES, et al. An evaluation of buccal infiltrations and inferior alveolar nerve blocks in pulpal anesthesia for mandibular first molars. J Endod 2008;34(1):11-13. DOI: 10.1016/j.joen.2007.09.006.

15. Monteiro MR, Groppo FC, Haiter-Neto F, et al. $4 \%$ articaine buccal infiltration versus $2 \%$ lidocaine inferior alveolar nerve block for emergency root canal treatment in mandibular molars with irreversible pulpits: a randomized clinical study. Int Endod J 2015;48(2):145-152. DOI: 10.1111/iej.12293.

16. Poorni $S$, Veniashok B, Senthilkumar AD, et al. Anesthetic efficacy of four percent articaine for pulpal anesthesia by using inferior alveolar nerve block and buccal infiltration techniques in patients with irreversible pulpitis: a prospective randomized double-blind clinical trial. J Endod 2011;37(12):1603-1607. DOI: 10.1016/j.joen.2011. 09.009 .

17. Yilmaz K, Tunga U, Ozyurek T. Buccal infiltration versus inferior alveolar nerve block in mandibular 2(nd) premolars with irreversible pulpitis. Niger J Clin Pract 2018;21(4):473-477. DOI: 10.4103/njcp. njcp_135_17.

18. Alinejhad D, Bahrololoomi Z, Navabazam A, et al. Comparison of visual analog scale scores in pain assessment during pulpotomy using different injection materials in children aged 6 to 8 and 8 to 10 years. J Contemp Dent Pract 2018;19(3):313-317. DOI: 10.5005/ jp-journals-10024-2259.

19. Alzahrani F, Duggal MS, Munyombwe T, et al. Anaesthetic efficacy of $4 \%$ articaine and $2 \%$ lidocaine for extraction and pulpotomy of mandibular primary molars: an equivalence parallel prospective randomized controlled trial. Int J Paediatr Dent 2018;28(3):335-344. DOI: 10.1111/ipd.12361.

20. Arali V, Mytri M. Anaesthetic efficacy of $4 \%$ articaine mandibular buccal infiltration compared to $2 \%$ lignocaine inferior alveolar nerve block in children with irreversible pulpitis. J Clin Diagn Res 2015;9(4):Zc65-Zc67. DOI: 10.7860/JCDR/2015/12821.5856.

21. Arrow P. A comparison of articaine $4 \%$ and lignocaine $2 \%$ in block and infiltration analgesia in children. Aust Dent J 2012;57(3):325-333. DOI: 10.1111/j.1834-7819.2012.01699.x.

22. Chopra R, Marwaha M, Bansal K, et al. Evaluation of buccal infiltration with articaine and inferior alveolar nerve block with lignocaine for pulp therapy in mandibular primary molars. J Clin Pediatr Dent 2016;40(4):301-305. DOI: 10.17796/1053-4628-40.4.301.

23. Ghadimi S, Shahrabi M, Khosravi Z, et al. Efficacy of articaine infiltration versus lidocaine inferior alveolar nerve block for pulpotomy in mandibular primary second molars: a randomized clinical trial. J Dent Res Dent Clin Dent Prospects 2018;12(2):97-101. DOI: 10.15171/joddd.2018.015. 
24. Jorgenson K, Burbridge L, Cole B. Comparison of the efficacy of a standard inferior alveolar nerve block versus articaine infiltration for invasive dental treatment in permanent mandibular molars in children: a pilot study. Eur Arch Paediatr 2020;21(1):171-177. DOI: 10.1007/s40368-019-00496-8.

25. Venkat Narayanan J, Gurram P, Krishnan R, et al. Infiltrative local anesthesia with articaine is equally as effective as inferior alveolar nerve block with lidocaine for the removal of erupted molars. Oral Maxillofac Surg 2017;21(3):295-299. DOI: 10.1007/s10006-017-0628-z.

26. Zain M, Rehman Khattak SU, Sikandar H, et al. Comparison of anaesthetic efficacy of $4 \%$ articaine primary buccal infiltration versus $2 \%$ lidocaine inferior alveolar nerve block in symptomatic mandibular first molar teeth. J Coll of Physicians Surg Pak 2016;26(1):4-8. DOI: 01.2016/JCPSP.0408. 